\title{
A Review on Researches of interaction between heavy metals and
}

\section{microalgae in water}

\author{
Liu Dongmei ${ }^{1, a}$, Fu Yiwei ${ }^{\star 2, b}$,Sun Hui ${ }^{3, c}$ \\ 1.School of Municipal and Environmental Engineering, Harbin Institute of Technology, Harbin \\ 150090, China,2.State Key Laboratory of Urban Water Resources and Environments (SKLUWRE), \\ Harbin Institute of Technology, Harbin 150090, China

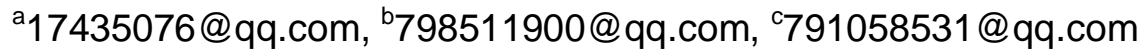

Keywords: Heavy metals; microalgae; toxic stress; detoxification

Abstract. As the development and utilization of heavy metals in human society more and more, along with the increasing number of heavy metals are released into the water, more and more of the heavy metals are discharged into water bodies. After the heavy metals are into the water, the primary producers of algae in water are affected first. When microalgae are on the stress of heavy metals, it will produce a series of physiological responses to response to environmental stress by itself. Therefore it also has a detoxification mechanism in a certain concentration range, which has great significance for sewage treatment using microalgae. In this paper, we described the toxicity of heavy metals and detoxification mechanisms of microalgae when microalgae in the environment with heavy metals. And we prospected the follow-up research on microalgae detoxification.

\section{Introduction}

Heavy metals are a class of potentially harmful contaminants. When heavy metals get into the water through various means, the first victims are algae. When microalgae have a long-term state with heavy metals stress in water, it will produce a series of corresponding adaptive mechanisms to mitigate the hazards of heavy metals on algae. Microalgae can make their own heavy metal concentration be maintained within a certain range of levels by absorption, accumulation, transfer, discharge of the heavy metals. Thus it can minimize the effects by heavy metals, ensuring its own growth.

\section{The toxicity of heavy metals on microalgae}

There are two roles of effects of heavy metals on microalgae. On the one hand, some heavy metals are essential trace elements in algae growth, such as Fe, Mo, etc. But these essential trace elements also need to be controlled within a certain range of concentrations. On the other hand, some heavy metals will have toxic effects on algae ${ }^{[2]}$. The toxic effects of heavy metals on the microalgae is mainly reflected in the way of hindering cell division, inhibiting the photosynthesis as well as the synthesis of organic compounds, reducing the activity of enzyme, etc..

Absorption of microalgae to heavy metals. There are two parts of fast phase and slow phase in the absorption of microalgae to heavy metals, extracellular absorption and intracellular accumulation.

There are many ways for heavy metals into cells. The first type, when the essential elements get into the cells by specialized transport corridors for required elements such as $\mathrm{Na}^{+}, \mathrm{K}^{+}, \mathrm{Mg}^{2+}$, $\mathrm{PO}_{4}{ }^{3-}$, there will also be some heavy metal ions can use this channel into the cell. This process 
involves active transport and passive diffusion. For example, $\mathrm{Ni}^{2+}, \mathrm{Co}^{2+}, \mathrm{Zn}^{2+}$ can get into the cells through the channel of $\mathrm{Mg}^{2+}$. Since arsenate has similar structures as phosphate, it can also enter the cell through the channel of phosphate ${ }^{[6]}$.The second type, heavy metals can combine with protein (polypeptide) on cell surface and then get into the cells. The third type is ion exchange. When heavy metals combine with alginate, ion exchange is take placed with the ions such as $\mathrm{Na}^{+} 、 \mathrm{~K}^{+}$.

The impact of heavy metals on biomass of microalgae. In 1981,OECD provides an international standardization method for algal growth inhibition test.

Different heavy metals have different degrees of inhibition on different algae. For instance, Qian ${ }^{[8]}$ found that the EC50 is lower to Chlorella for $\mathrm{Cu}$ than $\mathrm{Cd}$. But the inhibition of $\mathrm{Cu}$ on Chroococcus pairs, Chlorella vulgaris and inhibitory concentration Anacystis Nidulans were then presented in the order from low to high, respectively $0.1 \mathrm{ppm}, 0.2 \mathrm{ppm}, 0.4 \mathrm{ppm}$.Despite the impact of heavy metals on algae vary widely, it is generally believed that heavy metals inhibit the division of algal cells thus affecting the growth of algae.

The toxic effects of the same heavy metals are different in different environmental conditions, and different microalgae optimum growth conditions are some different ${ }^{[9]}$.

The genotoxicity of heavy metals on microalgae cells. Heavy metals can directly inhibit the DNA damage repair, attack nucleic acid molecules, interfere with cell division and promote free radical chain reaction.

Under normal circumstances, $\mathrm{H}_{2} \mathrm{O}_{2}$ and $\mathrm{O}_{2}{ }^{-}$are not able to cause direct damage to the DNA molecule, but $\bullet \mathrm{OH}$ is able to close the destruct the close DNA molecules. However, the time of its existence is very short in a normal environment. When there is heavy metals, it can induce a large amount of $\bullet \mathrm{OH}$ from $\mathrm{H}_{2} \mathrm{O}_{2}$ and $\mathrm{O}_{2}{ }^{-}$thereby cause damaging effects on DNA. The process shown below: (M1, M2 represents two forms of heavy metals)

$$
\mathrm{M}_{1}+\mathrm{DNA} \mathrm{H}_{2} \mathrm{O}_{2} \rightarrow \mathrm{M}_{2}-\mathrm{DNA}+2 \mathrm{H}^{+}+\mathrm{O}_{2}^{-} \stackrel{\mathrm{H}_{2} \mathrm{O}_{2}}{\longrightarrow} \mathrm{M}_{2}+\mathrm{DNA}-\mathrm{OH}+. \mathrm{OH}
$$

It can be seen from the formula that the ability of metal ions on DNA is related to its ability to activate $\mathrm{H}_{2} \mathrm{O}_{2}$ and its affinity with DNA molecule.

The impact of heavy metals on photosynthesis of microalgae. While photosynthesis is closely related to algae growth, the effect of heavy metals on the photosynthesis of microalgae is not positively correlated with the growth of microalgae ${ }^{[6]}$.

Generally considered mainly due to the combination between an excess heavy metals and thylakoid membrane, hinders the synthesis of chlorophyll, and impacts of Hill reaction.

There are many entry points about the effects of heavy metals on the photosynthesis of microalgae. Algae chlorophyll a content size and chlorophyll fluorescence parameters are relatively common detected. Or direct measurement of oxygen production and carbon dioxide consumption.

Effects of different heavy metals on the photosynthesis of microalgae are different. Some can inhibit photosynthesis, while some heavy metals are essential elements for photosynthesis.

\section{Detoxification of Microalgae itself}

The microalgae have a series of detoxification to maintain their growth in water with heavy metal. Algae's detoxification will play a huge role in the water treatment process using algae.

The role of the cell surface. Some of the functional groups on the cell wall surface can adsorb $80 \%$ of the heavy metals. These groups include carboxyl (-COOH), hydroxyl (-OH), amino (-NH-), mercapto group (-SH) and phosphate groups. Because of the existence of these groups, the cell wall is negatively charged and then can be combined with the heavy metal ions in water by ion exchange mechanism. 
Many cyanobacteria have gum consists of polysaccharide, mucus or plastic sheath on the cell surface. These algae secrete polysaccharides will possible be secreted into the body of water during cell growth. EPS mostly is anionic polymer and capable of binding with heavy metals, which can play a protective role in the environment of heavy metals ${ }^{[3]}$. Volesky ${ }^{[6]}$ found that there is alginate on the Alginate surface can be combined with heavy metals and protect itself.

\section{The detoxification pathway of metallothionein.}

Phytochelatins( PCs). Phytochelatinis induced by heavy metal ion, and enzymatic synthesis of small peptides, which is rich in cysteine. PCs protect the organism mainly through the chelation with heavy metals.

PCs can be used to maintain the metal ion homeostasis by organisms. In the environment containing traces of metals, plants, fungi, and algae are still able to detect a small number of PCs.

For those heavy metals biological growth necessary but not excessive such as $\mathrm{Cu}, \mathrm{Zn}$, when the intracellular concentrations is too high Phytochelatin will work with the heavy metal complex as complexing agent, which makes it not separated in the cells. When in low intracellular concentrations, Phytochelatin will release the heavy metals, making the essential element in the cells maintained at a range of normal levels ${ }^{[1]}$.For toxic heavy metals PCs can also play the role of detoxification. But now it is proven that only $\mathrm{Ag}^{+}, \mathrm{Cd}^{2+}, \mathrm{Hg}^{2+}, \mathrm{Pb}^{2+}, \mathrm{As}^{3+}, \mathrm{Cu}^{2+}, \mathrm{Zn}^{2+[1]}$ and so a small part. PCs alleviate heavy metal stress mainly by complexation with these heavy metals to format non-toxic compound and then decrease the intracellular concentration of heavy metal ions.

Metallothionein(MTs). Metallothionein is a class of cysteine-rich low molecular weight metal-binding protein, having an affinity for heavy metal, which is closely related to the presence of metal stress. MTs are a scavenger for active oxygen. MTs combine with heavy metals primarily by mercapto to reduce the toxicity of heavy metals. These heavy metals include $\mathrm{Cu}$ and $\mathrm{Zn}$. Heavy metals such as $\mathrm{Cd}^{2+}, \mathrm{Bi}^{3+}, \mathrm{Ag}+, \mathrm{Cu}^{2+}, \mathrm{Hg}^{2+}$, etc. can all induce the synthesis of MTs in the living cells and outside the organism's cells ${ }^{[7]}$.

The presence MTs have been confirmed in cyanobacteria Synechococcus. For eukaryotic algae, there may be MTs in brown algae Fucusvesiculosus, since the separation of gene for synthesis MTs. There are two hypotheses about the exact function of MTs. One theory is that, MTs is a repository of heavy metals ions intracellular or isolate heavy metals. Another hypothesis is that it mainly achieve detoxification through transport function. The heavy metals at a high concentration is transferred to a lower place or transported to the place does not cause toxic effects. It remains to be further studied to prove about the role of MTs in the process of algae's detoxification.

The detoxification pathway of cellular enzymes. In the process of microalgae exposed to heavy metals, ROS induced will have a strong toxic effects on the microalgae ${ }^{[6]}$.

SOD candismutase $\mathrm{O}_{2}^{-}$into $\mathrm{H}_{2} \mathrm{O}_{2}$. SOD is the first line of defense against ROS for cells, affecting the levels of $\mathrm{H}_{2} \mathrm{O}_{2}$ and $\mathrm{O}_{2}^{-}$. The research of changes of the concentration of SOD after the heavy metals act on the organism is very much.

The main role of CAT in peroxidase system is metabolizing $\mathrm{H}_{2} \mathrm{O}_{2}$ generated in the process of life activities to $\mathrm{H}_{2} \mathrm{O}$ and $\mathrm{O}_{2}$, and transform the glycolate produced in the breathing into glyoxylate. Same as SOD, activity of CAT under heavy metal stress also varied. APX is the same as CAT, playing an important role in removing $\mathrm{H}_{2} \mathrm{O}_{2}$.

The role of the vacuole compartment. Vacuolar compartmentalization plays an important role in the process of higher plants' detoxification to heavy metals. Vacuolar compartmentalization is regarded as the key of second-generation technology in bioremediation. Heuillet ${ }^{[4]}$ exposed Dunaliellabioculata to Cd-containing environment, and analysis by X-ray microanalysis. He found $\mathrm{Cd}$ and Sin the vacuole after 20 days. Nassiri also detected Cd and S in the Skeletonemacostatum's 
vacuoles which is common stressed in $\mathrm{Cu}$ and $\mathrm{Cd}$. And vacuole has increased in heavy metal stress. Complex of heavy metals-PCs formed in the process of detoxification plays an important role. Sulfur appears in algal cells. There is talk that PCs and heavy metal compound to form a low molecular weight compound, after binding $\mathrm{S}$ formed polymer composite of heavy metals-PCs into the vacuole. But specific how composite enter bubble is for further study.

\section{Prospect}

As a universal biological in water as well as the primary producers of nature, once the algae accumulation of heavy metals, it is easy to zoom through the food chain, and ultimately affects human health. Therefore, it is important to study its behavior in water. When the algae exposed to heavy metal in the water, it can continue to grow in a certain concentration range, and adapts to the adverse external environment through its own series of physiological changes, which has great significance in the use of algae. Current research on the use of algae to treat pollution of water bodies has been a lot. However, due to the algae is a living body itself, its life activity will be affected by pollutants. Once the detoxification mechanism of microalgae can be mastered by people, it has a milestone for the use of algae. Research on microalgae detoxification should get more in-depth research. It needs for further research from the cellular level, molecular level. And it will promote the development of other areas.

\section{Acknowledgements}

This paper is Supported by National Natural Science Foundation of China (Grant No. 50808052), National Water Special Program of China (2012ZX07403-001), and State Key Laboratory of Urban Water Resource and Environment (Harbin Institute of Technology ) （No 2014TS02）.

\section{References}

[1] Adrees M, Ali S, Rizwan M, et al. The effect of excess copper on growth and physiology of important food crops: a review[J]. Environmental Science and Pollution Research, 2015, 22(11): 8148-8162.

[2] Liu DM, Wang ZW, Zhu Q, et al. Drinking water toxicity study of the environmental contaminant—Bromate[J]. Regulatory Toxicology and Pharmacology, 2015, 73(3): 802-810.

[3] Guo P Y, Liu Y, Wen X, et al. Effects of algicide on the growth of Microcystisflos-aquae and adsorption capacity to heavy metals[J]. International Journal of Environmental Science and Technology, 2015, 12(7): 2339-2348.

[4] Heuillet E, Noreau A, Halpern S, et al. Cadmium binding to a thiol-molecule in vacuoles of Dunaliellabioculata contaminated with CdCl2[J]. Biology of the Cell, 1986, 58(1): 79-85.

[5] Munoz L P, Purchase D, Jones $\mathrm{H}$, et al. The mechanisms of detoxification of As (III), dimethylarsinic acid (DMA) and As (V) in the microalga Chlorella vulgaris[J]. Aquatic Toxicology, 2016, 175: 56-72.

[6] Nielsen H D, Nielsen S L. Photosynthetic responses to $\mathrm{Cu}^{2+}$ exposure are independent of light acclimation and uncoupled from growth inhibition in Fucusserratus (Phaeophyceae). Mar Pollut Bull, 2005, 51: 715-721.

[7] Patzelt D J, Hindersin S, Kerner M, et al. Responses of photosystems I and II of Acutodesmusobliquus to chemical stress caused by the use of recycled nutrients[J]. Applied microbiology and biotechnology, 2016, 100(1): 361-370. 
[8] Qian H F, Li J J, Sun L W, et al. Combined effect of copper and cadmium on Chlorella vulgaris growth and photosynthesis-related gene transcription. AquatToxicol, 2009, 94: 56-61.

[9] Zhao N, Zhu L,Feng M F,et al.Toxic effects of $\mathrm{C}^{\mathrm{rt}+}$ to 3 kinds of algae under different $\mathrm{pH}$ conditions.Ecotoxicology newspaper,2010(05): 657-665. 